\title{
Metabolic Studies in Familial Hypercholesterolemia
}

\author{
EVIDENCE FOR A GENE-DOSAGE EFFECT IN VIVO
}

\author{
DAVID W. BilheImer, Department of Internal Medicine, University of Texas Health \\ Science Center at Dallas, Dallas, Texas 75235 \\ NeIL J. Stone, Department of Medicine, Northwestern University Medical School, \\ Chicago, Illinois 60611 \\ ScotT M. GRUNDY, Department of Medicine, School of Medicine, University of \\ California, San Diego, and Veterans Administration Hospital, San Diego, \\ California 92161
}

\begin{abstract}
A B S T R A C T To investigate the gene-dosage effect in familial hypercholesterolemia $(\mathrm{FH})$, metabolic studies were conducted in a group of well-characterized patients with either heterozygous $(n=7)$ or homozygous $(n=7)$ FH and the results were compared to those obtained in normal subjects $(n=6)$. The turnover of ${ }^{125}$ I-labeled low-density lipoprotein (LDL) was measured in all of the normals, all but one of the FH heterozygotes, and in all of the homozygotes. Chemical cholesterol balance was performed simultaneously with the ${ }^{125}$ I-LDL turnover in all seven of the homozygotes.
\end{abstract}

With regard to ${ }^{125}$ I-LDL turnover, FH homozygotes, who possess two doses of the mutant FH gene, exhibited a threefold increase in the rate of apoLDL synthesis while the fractional catabolic rate (FCR) for the apoprotein was only about one-third of normal. Heterozygotes, who have only one dose of the mutant FH gene, exhibited intermediate values for both parameters; that is, the FCR was two-thirds of normal and the apoLDL synthetic rate was 1.7 -fold greater than normal.

The data indicate that the single gene defect in FH produces two distinct abnormalities of LDL metabolism: (a) an increase in the synthetic rate for apoLDL and (b) a decrease in the efficiency of apoLDL catabolism. Both defects are more severe in FH homozygotes than in heterozygotes.

The FCR for apoLDL in the homozygotes appeared to be fixed at $\cong 17 \% / d$ whereas the plasma LDL level varied about twofold. These findings suggest that the twofold variation in plasma LDL levels observed in

Dr. Bilheimer is an Established Investigator of the American Heart Association.

Received for publication 8 December 1978 and in revised form 23 April 1979. these seven patients is caused by variation in the plasma apoLDL synthetic rates. Consistent with this conclusion was the finding that the correlation between the plasma LDL level and the apoLDL synthetic rates in the seven FH homozygotes was 0.943 .

The rate of total body cholesterol synthesis determined by chemical cholesterol balance did not appear to clearly differ between normals and patients with either one or two mutant FH genes. Two of the youngest FH homozygotes exhibited cholesterol overproduction but the other five did not. No consistent abnormality of bile acid metabolism was observed in these patients. Because the daily plasma flux of cholesterol on LDL is about threefold greater than the amount of cholesterol produced per day, a significant amount of the cholesterol liberated from LDL degradation must be reused.

\section{INTRODUCTION}

Familial hypercholesterolemia $(\mathbf{F H})^{1}$ is a common inherited disorder of plasma lipoprotein metabolism that causes increased low-density lipoprotein (LDL) concentrations in the plasma $(1,2)$. FH constitutes one of the rare genetic diseases in man in which homozygotes for a dominant trait exist. Studies of these homozygotes have revealed that the $\mathrm{FH}$ mutation produces a gene-dosage effect. Homozygotes, who have two doses of the mutant gene, exhibit higher LDL levels and a more severe clinical syndrome than do heterozygotes who have one dose of the mutant gene $(1,2)$.

\footnotetext{
${ }^{1}$ Abbreviations used in this paper: FCR, fractional catabolic rate; FH, familial hypercholesterolemia; HDL, high-density lipoprotein; LDL, low-density lipoprotein; $U: P$, ratio of total urinary radioactivity excreted in each 24 -h period to the mean plasma radioactivity during that same interval; VLDL, very low-density lipoprotein.
} 
The gene-dosage effect in $\mathrm{FH}$ provides a unique opportunity to compare the rates of synthesis and degradation of a plasma lipoprotein in individuals with either one or two abnormal alleles at a single locus controlling LDL metabolism. Moreover, interpretation of the results of LDL turnover studies is facilitated by the demonstration that the genetic defect in FH involves the gene encoding a cell surface receptor for LDL. Studies in tissue culture $(3,4)$ and in freshly isolated human lymphocytes (5-7) have demonstrated that this receptor normally facilitates the cellular uptake and degradation of plasma LDL, supplying cholesterol to body cells and simultaneously suppressing their endogenous cholesterol synthesis. Fibroblasts and lymphocytes from FH heterozygotes express half the normal number of LDL receptors and hence degrade LDL at half the normal rate $(3,7)$. Fibroblasts from FH homozygotes express an absence or near-absence of LDL receptor activity and therefore show no highaffinity degradation of $\operatorname{LDL}(3,4)$.

The question then arises: how is this receptor abnormality translated in vivo into a two- to threefold elevation in plasma LDL levels in FH heterozygotes and a four- to eightfold elevation in FH homozygotes? Early studies of plasma ${ }^{125}$ I-LDL turnover in FH heterozygotes indicated that the fractional catabolic rate (FCR) for LDL was reduced by $\cong 60 \%$ in these subjects as compared to normals (8), whereas the synthetic rate for LDL was the same in the heterozygotes and in the normal controls (8). Subsequent studies of ${ }^{125}$ I-LDL turnover in FH homozygotes indicated that these subjects exhibited a dual defect: the FCR for LDL was reduced to about one-third of normal, whereas LDL production was up to fourfold greater than normal (9-11).

These previous ${ }^{125}$ I-LDL turnover studies involved FH heterozygotes and homozygotes studied in different laboratories. Moreover, these studies were performed before the recognition that patients with FH can have any of at least three different mutations at the LDL receptor locus. One of these, termed $\left(R^{b^{0}}\right)$, specifies a receptor that does not bind LDL in detectable amounts (4). Another of these alleles $\left(\mathbf{R}^{\mathrm{b}-}\right)$ specifies a receptor that can bind up to $10 \%$ of the normal amount of LDL (12). The third allele $\left(R^{b+},{ }^{10}\right)$ specifies a receptor that can bind but not transport LDL into cells for degradation $(13,14)$.

In the current study, we have compared ${ }^{125}$ I-LDL metabolism in a series of intact subjects with welldefined types of FH. In addition, we have studied total body cholesterol synthesis in these patients by the sterol balance technique. The results indicate that there are proportional abnormalities in LDL metabolism consistent with a gene-dosage effect that influences both LDL synthesis and LDL degradation.

\section{METHODS}

Patients. The study included 20 subjects. Six were normolipidemic, seven had heterozygous FH, and seven had homozygous FH. The six normal subjects were free-living individuals who responded to a general request for normal volunteers to participate in the lipoprotein turnover study. Five were Caucasian and one (J.Ch.) was an American Indian. Routine clinical laboratory tests indicated that these individuals were free of diabetes mellitus, thyroid disease, hepatic disease, or renal dysfunction. The pertinent clinical data for these subjects are outlined in Table $\mathbf{I}$.

The FH heterozygotes were selected either because they were parents of a homozygous child or because they were members of a kindred with heterozygous FH. Both M.M. and J.C. were mothers of homozygous children (J.M. and M.C., respectively), K.M. was the sister of a homozygote (J.M.), and the other four patients were members of a large kindred with FH that was previously reported (7). Pertinent clinical data on these patients is included in Table I. Data on two additional young heterozygotes (L.C. and Je.Ch.) have been previously reported (11) but are included in Tables I, III, and IV to permit ready comparisons.

The pertinent clinical data concerning the patients with homozygous FH are contained in Table II.

Informed consent was obtained from each patient and, when necessary, from his or her parent or guardian.

Diets. The normal subjects and four of the patients with heterozygous FH (R.M., B.O., M.B., and C.C.) were studied while consuming an isocaloric diet containing $20 \%$ of the calories as protein, $40 \%$ as fat, and $40 \%$ as carbohydrate. The cholesterol content was limited to $300 \mathrm{mg} / \mathrm{d}$ and the polyunsaturate-to-saturate fat ratio was $\cong 1.5$.

Those patients participating in a chemical cholesterol balance either alone or simultaneously with a ${ }^{125} \mathrm{I}-\mathrm{LDL}$ turnover study consumed an isocaloric, low cholesterol, partial solid food diet to facilitate the balance study. This diet was formulated from a lard base as previously described (15), and on average, contained $19 \%$ of the calories as protein, $37 \%$ as fat, and $44 \%$ as carbohydrate. The cholesterol content is listed in Table IV.

Lipoprotein turnover studies. 10-14 d after admission to the metabolic ward, plasma was obtained from each patient by plasmapheresis with standard citrate-phosphate-dextrose anticoagulant and then dialyzed for $24 \mathrm{~h}$ against 12 liters of solution containing $0.15 \mathrm{M} \mathrm{NaCl}, 0.1 \%$ EDTA, pH 7.4 $(d=1.006 \mathrm{~g} / \mathrm{ml})$. Details for the preparation of the ${ }^{125} \mathrm{I}-\mathrm{LDL}$ have been published (11). The efficiency of iodination ranged between 8 and $37 \%$. The degree of lipid labeling of the ${ }^{125}$ I-LDL determined by chloroform:methanol extraction $(2: 1, \mathrm{vol} / \mathrm{vol})$ varied between 0.6 and $7.5 \%$. Greater than $97 \%$ of the radioactivity in the ${ }^{125} \mathrm{I}-\mathrm{LDL}$ was precipitated with TCA and the ${ }^{125}$ I-LDL was indistinguishable from native LDL electrophoretically (16), immunologically (17), and biologically as determined by its ability to suppress 3-hydroxy-3-methylglutaryl coenzyme A reductase activity in human fibroblasts (18).

Each lipoprotein turnover study was initiated by injecting autologous ${ }^{125}$ I-LDL through a running intravenous line kept open with normal saline. From 0.3 to $6.0 \mathrm{mg}$ of LDL protein was injected in a volume not exceeding $2 \mathrm{ml}$. The amount of radioactivity injected varied directly with the body weight and ranged from 12.5 to $50 \mu \mathrm{Ci}$. Plasma volume was calculated by the isotope dilution technique with the 10-min sample (8). Serial blood samples and 24-h urine collections were obtained and analyzed as previously reported $(11,19)$. Plasma and urine samples were assayed for radioactivity in a Packard Model 5285 Autogamma scintillation spectrometer (Packard Instrument Co., Inc., Downers Grove, Ill.). 
The kinetic parameters for LDL turnover were calculated as described (11). The apoLDL concentration was calculated from the measured value for LDL-cholesterol and the measured ratio of protein to cholesterol in each patient's LDL. During the ${ }^{125 I-L D L}$ turnover study, each patient received 500-700 mg of iodine daily in divided doses in the form of a saturated solution of potassium iodide (8).

Measurement of plasma cholesterol and triglyceride levels. These measurements were made as described (11) with the exception that the plasma cholesterol determinations were performed with a commercially available enzyme method (Boehringer Mannheim Biochemicals, Indianapolis, Ind.; catalogue 124087) standardized with commercially available cholesterol standards (Boehringer Mannheim Biochemicals; catalogue 125512). Moni-Trol I Serum (American Hospital Supply Corp., Evanston, Ill.) and Precilip Serum (Boehringer Mannheim Biochemicals; catalogue 125067) served as control sera.

Measurement of plasma lipoproteins. Lipoprotein concentrations in plasma were estimated by standard techniques as described (11).

Cholesterol balance studies. Chemical cholesterol balance was performed according to described methods with $\beta$-sitosterol and chromium oxide as internal standards $(15,20)$. Serial 4-d stool collections were performed while the patients were consuming the lard-base diet. The stools were frozen until the study was completed; each collection was then homogenized, and aliquots were taken for sterol analyses which were performed at the University of California at San Diego.

Blood chemistries. Routine blood chemistry determinations were performed by standard techniques in the metabolic laboratory associated with the Clinical Research Center at the University of Texas Health Science Center at Dallas or, for the study of J.D., at the Northwestern University Clinical Research Center.

Statistical analyses. Statistical analyses were performed with the Kruskal-Wallis analysis of variance followed by the nonparametric multiple comparisons procedure $(21)$.

\section{RESULTS}

Evidence for a metabolic steady state. Several lines of evidence suggest that each patient maintained a relatively steady metabolic state during each study. First, calorie intake was constant as reflected by the absence of any significant weight change (Tables I and II). Second, plasma lipids in each patient showed little variation throughout the study (Tables I and II). Third, fecal steroid excretion in each of the patients studied by sterol balance was relatively constant during each study (Table IV).

LDL turnover in normal subjects. The mean age

TABLE I

Clinical Data on Normal Subjects and FH Heterozygotes During ${ }^{125}$ I-LDL Turnover and(or) Chemical Cholesterol Balance Studies*

\begin{tabular}{|c|c|c|c|c|c|c|c|c|}
\hline \multirow[b]{2}{*}{ Subject } & \multirow[b]{2}{*}{ Age } & \multirow[b]{2}{*}{ Sex } & \multirow[b]{2}{*}{ Weight } & \multirow[b]{2}{*}{ Height } & \multicolumn{3}{|c|}{ Plasma cholesterol } & \multirow{2}{*}{$\begin{array}{c}\text { Plasma } \\
\text { triglyceride }\end{array}$} \\
\hline & & & & & Total & LDL & HDL & \\
\hline & $y r$ & & $k g$ & $\mathrm{~cm}$ & & $m g / d l$ & & $m g / d l$ \\
\hline \multicolumn{9}{|c|}{ Normal subjects } \\
\hline J.Ch. & 22 & $\mathbf{M}$ & $52.4 \pm 0.1$ & 166.4 & $104 \pm 3$ & $58 \pm 4$ & $36 \pm 3$ & $47 \pm 6$ \\
\hline R.P. & 24 & $\mathbf{M}$ & $85.5 \pm 0.3$ & 189.7 & $144 \pm 5$ & $85 \pm 3$ & $31 \pm 6$ & $102 \pm 8$ \\
\hline J.W. & 26 & $\mathbf{F}$ & $64.9 \pm 0.3$ & 160.0 & $144 \pm 3$ & $77 \pm 4$ & $53 \pm 3$ & $60 \pm 10$ \\
\hline P.D. & 26 & $\mathbf{F}$ & $58.8 \pm 0.2$ & 162.6 & $149 \pm 4$ & $89 \pm 2$ & $42 \pm 2$ & $60 \pm 8$ \\
\hline I.K. & 27 & $\mathbf{M}$ & $72.8 \pm 0.3$ & 189.7 & $137 \pm 10$ & $79 \pm 9$ & $25 \pm 3$ & $129 \pm 15$ \\
\hline D.A. & 28 & $\mathbf{F}$ & $64.1 \pm 0.4$ & 176.3 & $129 \pm 4$ & $69 \pm 2$ & $48 \pm 5$ & $55 \pm 7$ \\
\hline Mean \pm SD & $26 \pm 2$ & & $66.4 \pm 11.6$ & $174.1 \pm 13.3$ & $135 \pm 16$ & $76 \pm 11$ & $39 \pm 11$ & $76 \pm 32$ \\
\hline \multicolumn{9}{|l|}{ Heterozygotes } \\
\hline R.M.† & 22 & $\mathbf{F}$ & $50.9 \pm 0.3$ & 153.8 & $283 \pm 17$ & $233 \pm 23$ & $36 \pm 3$ & $80 \pm 11$ \\
\hline B.O. & 28 & $\mathbf{F}$ & $55.3 \pm 0.3$ & 156.4 & $251 \pm 10$ & $202 \pm 14$ & $38 \pm 2$ & $55 \pm 4$ \\
\hline J.C. $\$$ & 30 & $\mathbf{F}$ & $59.6 \pm 0.3$ & 157.5 & $333 \pm 9$ & $199 \pm 22$ & $85 \pm 9$ & $97 \pm 23$ \\
\hline M.M. & 31 & $\mathbf{F}$ & $49.0 \pm 0.3$ & 160.0 & $318 \pm 16$ & $239 \pm 9$ & $54 \pm 4$ & $62 \pm 10$ \\
\hline M.B.t & 31 & $\mathbf{M}$ & $63.7 \pm 0.9$ & 171.8 & $299 \pm 32$ & $238 \pm 33$ & $21 \pm 3$ & $120 \pm 17$ \\
\hline C.C. $\ddagger$ & 44 & $\mathbf{F}$ & $67.9 \pm 0.1$ & 160.7 & $468 \pm 22$ & $266 \pm 20$ & $56 \pm 10$ & $183 \pm 13$ \\
\hline Mean \pm SD & $31 \pm 7$ & & $57.7 \pm 7.4$ & $160.0 \pm 6.3$ & $325 \pm 76^{\prime \prime}$ & $230 \pm 25^{\prime \prime}$ & $48 \pm 22$ & $100 \pm 47$ \\
\hline \multicolumn{9}{|c|}{ Young heterozygote } \\
\hline K.M.I & 8 & $\mathrm{~F}$ & $26.3 \pm 0.2$ & 125.1 & $255 \pm 13$ & $202 \pm 12$ & $45 \pm 4$ & $57 \pm 10$ \\
\hline
\end{tabular}

* All values are expressed as the mean \pm 1 SD of observations made during the course of these studies.

\$ These four heterozygotes are members of the $\mathrm{D}$ family whose pedigree is shown in Fig. 5 of reference 7 . The pedigree position of R.M., B.O., M.B., and C.C. are IV-32, IV-17, IV-15, and III-19, respectively.

From reference 11 .

" $P<0.05$.

I Participated only in chemical cholesterol balance. 
TABLE II

Clinical Data on FH Homozygotes During ${ }^{125}$ I-LDL Turnover and Chemical Cholesterol Balance Studies*

\begin{tabular}{|c|c|c|c|c|c|c|c|c|c|c|}
\hline \multirow[b]{2}{*}{ Subject } & \multirow[b]{2}{*}{ Age } & \multirow[b]{2}{*}{ Sex } & \multirow[b]{2}{*}{ Weight } & \multirow[b]{2}{*}{ Height } & \multicolumn{3}{|c|}{ Plasma cholesterol } & \multirow{2}{*}{$\begin{array}{c}\text { Plasma } \\
\text { triglyceride }\end{array}$} & \multirow{2}{*}{$\begin{array}{l}\text { LDL receptor } \\
\text { activity } ₫\end{array}$} & \multirow[b]{2}{*}{ Comments } \\
\hline & & & & & Total & LDL & HDL & & & \\
\hline & $y r$ & & $k g$ & $\mathrm{~cm}$ & & $m g / d l$ & & $m g / d l$ & $\%$ & \\
\hline M.C. $\$$ & 7 & $\mathbf{F}$ & $20.7 \pm 0.1$ & 121.9 & $997 \pm 47$ & $801 \pm 28$ & $89 \pm 7$ & $112 \pm 16$ & $<2$ (Receptor-negative) & $\begin{array}{l}\text { Cutaneous xanthomas; aortic ste- } \\
\text { nosis and diffuse coronary ath- } \\
\text { erosclerosis; atherosclerosis of } \\
\text { aortic root; angina pectoris. } \\
\text { Daughter of J.C. }\end{array}$ \\
\hline F.W. & 13 & $\mathbf{F}$ & $53.6 \pm 0.2$ & 161.3 & $432 \pm 26$ & $386 \pm 25$ & $28 \pm 4$ & $57 \pm 15$ & $<2$ (Receptor-negative) & $\begin{array}{l}\text { Numerous cutaneous xanthomas; } \\
\text { tendon xanthomas; murmur of } \\
\text { aortic stenosis; vascular bruits. }\end{array}$ \\
\hline B.H. & 21 & $\mathbf{M}$ & $96.0 \pm 0.6$ & 182.9 & $626 \pm 28$ & $535 \pm 20$ & $26 \pm 4$ & $117 \pm 17$ & $<2$ (Receptor-negative) & $\begin{array}{l}\text { Xanthelasmas; arcus cornea and } \\
\text { numerous cutaneous xantho- } \\
\text { mas; tendon xanthomas; angina } \\
\text { pectoris; systolic heart mur- } \\
\text { mur; vascular bruits. }\end{array}$ \\
\hline J.M. & 5 & $\mathbf{M}$ & $17.0 \pm 0.1$ & 110.5 & $591 \pm 19$ & $508 \pm 26$ & $44 \pm 3$ & $64 \pm 8$ & 5 (Receptor-defective) & $\begin{array}{l}\text { Arcus cornea; cutaneous xantho- } \\
\text { mas; tendon xanthoma; systolic } \\
\text { heart murmur. Son of M.M. }\end{array}$ \\
\hline S.W. & 6 & $\mathbf{F}$ & $21.4 \pm 0.3$ & 114.3 & $919 \pm 50$ & $843 \pm 52$ & $37 \pm 3$ & $115 \pm 16$ & 5 (Receptor-defective) & $\begin{array}{l}\text { Arcus cornea; cutaneous xantho- } \\
\text { mas; systolic heart murmur; } \\
\text { vascular bruits. }\end{array}$ \\
\hline D.R. & 15 & $\mathbf{F}$ & $47.9 \pm 0.3$ & 158.7 & $509 \pm 22$ & $432 \pm 22$ & $28 \pm 3$ & $123 \pm 3$ & 15-20 (Receptor-defective) & Cutaneous xanthomas. \\
\hline J.D. & 15 & $\mathbf{M}$ & $56.7 \pm 0.4$ & 161.5 & $573 \pm 13$ & $472 \pm 10$ & $17 \pm 1$ & $148 \pm 26$ & Internalization-defect & $\begin{array}{l}\text { Cutaneous and tendon xantho- } \\
\text { mas; aortic stenosis and aortic }\end{array}$ \\
\hline Mean \pm SD & $11.7 \pm 5.9$ & & $44.8 \pm 28.1$ & $144.4 \pm 28.4$ & $664 \pm 212 \pi$ & $568 \pm 180$ ㅇ & $38 \pm 24$ & $105 \pm 33$ & & $\begin{array}{l}\text { regurgitation; coronary ather- } \\
\text { osclerosis. }\end{array}$ \\
\hline
\end{tabular}

* All values are expressed as the mean $\pm 1 \mathrm{SD}$ of observations made during the course of these studies.

1 Measured in cultured fibroblasts $(4,12)$ as described in the referenced articles.

$\$$ From reference 11 .

"See references 13 and 14.

I $P<0.05$.

of the normal subjects was $26.2 \mathrm{yr}$ and their mean wt was $66.4 \pm 11.6 \mathrm{~kg}$. Their mean total plasma cholesterol was $163 \pm 22 \mathrm{mg} / \mathrm{dl}$ upon entry to the hospital (data not shown) and dropped to $135 \pm 16 \mathrm{mg} / \mathrm{dl}$ after $10 \mathrm{~d}-2 \mathrm{wk}$ on a low-cholesterol diet. These study values are similar to those reported by Connor (22) in young subjects consuming a low-cholesterol diet. The mean LDLcholesterol in this group was $76 \pm 11 \mathrm{mg} / \mathrm{dl} .{ }^{2}$ The mean FCR calculated from the plasma die-away curve with a two-compartment model $(8,11)$ was $0.450 \pm 0.072 / \mathrm{d}$, a value closely approximating the mean FCR of 0.436 $\pm 0.074 / \mathrm{d}$ obtained by relating the daily urinary excretion rate of ${ }^{125}$ I radioactivity to the ${ }^{125}$ I radioactivity in plasma ( $U: P$ ratio) $(8,11)$. When the absolute rate of synthesis of apoLDL was normalized for body weight, the mean synthetic rate was $8.0 \pm 0.7 \mathrm{mg} / \mathrm{kg}$ per $\mathrm{d}$. Of the total amount of apoLDL in the body, $60.5 \pm 6.7 \%$ was calculated to be in the intravascular space. There were no obvious differences between the sexes with regard to the principal apoLDL turnover parameters (half-life, FCR, synthetic rate, and the percent total apoLDL in the body contained within the intravascular space)

\footnotetext{
${ }^{2}$ The LDL-cholesterol in all three study groups was measured on the $d=1.019-1.063$ fraction of plasma LDL.
}

in this group but the number of observations for each sex was small.

The inclusion of one American Indian in the group of normals deserves comment because members of certain Indian tribes may have lower plasma cholesterol levels than do Caucasians. Although the total plasma cholesterol level was low in subject J.Ch., his LDL turnover parameters did not differ from the range of values observed in the normal Caucasians. Furthermore, if the results in this subject were excluded from the statistical analyses, none of the subsequent conclusions involving comparison with the other groups were altered (data not shown).

LDL turnover in $\mathrm{FH}$ heterozygotes. The mean age and body weight of the heterozygotes did not differ significantly from these parameters in the normal group (Table I). None of the subjects was obese. The unique feature of the heterozygotes was that four of the six were members of the same pedigree, and the other two were obligate heterozygotes in that they were mothers of FH homozygotes. Hence, the likelihood that the hypercholesterolemia in these six patients was caused by the FH gene was extremely high. The total plasma and LDL-cholesterol levels in this group were significantly elevated above normal, whereas the high-density lipo- 
TABLE III

Kinetic Parameters for ${ }^{125}$ I-LDL Turnover Studies

\begin{tabular}{|c|c|c|c|c|c|c|c|c|c|}
\hline \multirow{3}{*}{ Patient } & \multirow{3}{*}{$\begin{array}{c}\begin{array}{c}\text { Plasma } \\
\text { volume }\end{array} \\
m l\end{array}$} & \multirow{3}{*}{$\begin{array}{c}\begin{array}{c}\text { Plasma } \\
\text { apoLDL }\end{array} \\
m g / d l\end{array}$} & \multicolumn{2}{|c|}{$\begin{array}{c}t_{1 / 2} \text { for exponential } \\
\text { decay* }\end{array}$} & \multicolumn{2}{|c|}{ FCR! } & \multirow{2}{*}{\multicolumn{2}{|c|}{$\begin{array}{l}\text { Rate of synthesis and } \\
\text { catabolism of apoLDL }\end{array}$}} & \multirow{3}{*}{$\frac{\begin{array}{c}\text { Distribution } \\
\text { of apoLDL }\end{array}}{\%}$} \\
\hline & & & (a) & (b) & (c) & (d) & & & \\
\hline & & & \multicolumn{2}{|c|}{$d$} & \multicolumn{2}{|c|}{$d^{-1}$} & $m g / d$ & $m g / k g / d$ & \\
\hline \multicolumn{10}{|l|}{ Normal } \\
\hline J.Ch. & 2,158 & 36 & 0.9 & 3.8 & 0.541 & $0.450 \pm 0.142$ & 422 & 8.1 . & 54.4 \\
\hline R.P. & 3,353 & 51 & 1.2 & 3.8 & 0.381 & $0.458 \pm 0.093$ & 649 & $7.6^{\circ}$ & 69.4 \\
\hline J.W. & 2,458 & 54 & 0.9 & 3.7 & 0.437 & $0.353 \pm 0.108$ & 579 & 8.9 & 58.3 \\
\hline P.D. & 2,443 & 51 & 0.9 & 3.8 & 0.393 & $0.372 \pm 0.090$ & 490 & 8.3 & 62.8 \\
\hline I.K. & 2,650 & 47 & 1.5 & 4.8 & 0.409 & $0.423 \pm 0.108$ & 504 & 6.9 & 65.9 \\
\hline D.A. & 2,139 & 46 & 0.8 & 3.6 & 0.537 & $0.561 \pm 0.168$ & 523 & 8.2 & 52.1 \\
\hline Mean $\pm S D$ & & $48 \pm 6$ & $1.0 \pm 0.3$ & $3.9 \pm 0.4$ & $0.450 \pm 0.072$ & $0.436 \pm 0.074$ & $528 \pm 78$ & $8.0 \pm 0.7$ & $60.5 \pm 6.7$ \\
\hline \multicolumn{10}{|c|}{ Heterozygotes } \\
\hline R.M. & 2,090 & 135 & 0.8 & 3.9 & 0.307 & $0.288 \pm 0.025$ & 866 & 17.1 & 65.8 \\
\hline B.O. & 2,106 & 88 & 1.3 & 5.3 & 0.237 & $0.235 \pm 0.045$ & 437 & 7.9 & 68.0 \\
\hline J.C." & 2,286 & 137 & 1.0 & 3.3 & 0.334 & $0.322 \pm 0.022$ & 1,046 & 17.6 & 77.5 \\
\hline M.M. & 2,205 & 116 & 0.8 & 4.5 & 0.237 & $0.239 \pm 0.019$ & 605 & 12.3 & 69.5 \\
\hline M.B. & 2,033 & 138 & 1.3 & 5.5 & 0.304 & $0.360 \pm 0.062$ & 850 & 13.4 & 59.7 \\
\hline C.C. & 2,309 & 144 & 1.7 & 4.5 & 0.301 & $0.329 \pm 0.045$ & 1,001 & 14.7 & 75.1 \\
\hline Mean \pm SD & & $126 \pm 211$ & $1.2 \pm 0.4$ & $4.5 \pm 0.8$ & $0.287 \pm 0.040$ & $0.296 \pm 0.0519$ & $801 \pm 2367$ & $13.8 \pm 3.6 \pi$ & $69.3 \pm 6.3 \pi$ \\
\hline \multicolumn{10}{|l|}{ Homozygotes } \\
\hline M.C." & 989 & 569 & 0.6 & 6.5 & 0.153 & $0.142 \pm 0.009$ & 861 & 41.6 & 72.0 \\
\hline F.W. & 2,029 & 270 & 0.6 & 6.0 & 0.153 & $0.130 \pm 0.031$ & 838 & 15.6 & 78.5 \\
\hline B.H. & 3,123 & 316 & 1.2 & 6.1 & 0.173 & $0.169 \pm 0.031$ & 1,704 & 17.8 & 72.5 \\
\hline J.M. & 813 & 250 & 0.7 & 5.5 & 0.179 & $0.160 \pm 0.010$ & 364 & 21.4 & 74.2 \\
\hline S.W. & 1,117 & 513 & 0.9 & 7.4 & 0.144 & $0.121 \pm 0.018$ & 825 & 38.6 & 70.1 \\
\hline D.R. & 1,546 & 320 & 0.9 & 4.8 & 0.250 & $0.203 \pm 0.030$ & 1,243 & 25.9 & 65.2 \\
\hline J.D. & 2,565 & 298 & 0.8 & 5.4 & 0.178 & $0.200 \pm 0.015$ & 1,359 & 24.0 & 76.0 \\
\hline Mean \pm SD & & $362 \pm 126 \pi$ & $0.8 \pm 0.2$ & $6.0 \pm 0.8 \pi$ & $0.176 \pm 0.040$ - & $0.161 \pm 0.032 \uparrow$ & $1,028 \pm 439$ | & $26.4 \pm 10.0$ 에 & $72.6 \pm 4.37$ \\
\hline
\end{tabular}

* These data represent the $t_{1 / 2}$ of the first (a) and second (b) exponentials of the plasma die-away curve.

I Fraction of the intravascular apoLDL pool metabolized each day, calculated either from the two exponentials of the plasma die-away curve (c) or from the U:P ratio (d). $\$$ Percentage of total body apoLDL contained in the intravascular space.

"From reference 11 .

I $P<0.05$.

protein (HDL)-cholesterol and plasma triglyceride levels were not (Table I). Although the heterozygotes were slightly older than the normal subjects, the difference in the average age between these two groups was not significant. The mean plasma apoLDL concentration in the heterozygotes was 2.6-fold greater than normal.

The mean half-life of the second exponential of the apoLDL die-away curve for the heterozygotes was $4.5 \pm 0.8 \mathrm{~d}$, a value slightly greater than but not significantly different from normal. The mean FCR was significantly reduced from normal (Table III) and once again the mean FCR calculated from the plasma dieaway curve $(0.287 \pm 0.040 / \mathrm{d})$ agreed closely with the mean value derived from the U/P ratio $(0.296 \pm 0.051 / \mathrm{d})$. The finding of a reduced FCR in the heterozygotes confirmed the findings of previous reports $(8,11,23)$. The mean value for apoLDL synthesis normalized for body weight was 1.7 -fold greater than normal in the heterozygotes and only one of the six heterozygotes had an apoLDL synthetic rate in the normal range. The increased apoLDL synthetic rate in the hetero- zygotes was significantly different from normal (Table III).

Subjects M.M. and J.C. consumed lard-based partial formula diets during their lipoprotein turnover studies to determine whether or not this diet would markedly influence LDL turnover parameters. As can be seen from the data in Table III, the LDL turnover parameters measured in these two subjects fell within the range of values observed in the other four subjects, suggesting that the lard-based partial formula diet does not markedly influence LDL turnover.

LDL turnover in FH homozygotes. The FH homozygotes were younger and smaller than the members of the other two study groups but the shortened lifespan in this form of the disease precludes the study of older patients. There was a marked increase in the total plasma cholesterol level $(644 \pm 212 \mathrm{mg} / \mathrm{dl})$, which was accounted for solely by the increase in LDL-cholesterol $(568 \pm 180 \mathrm{mg} / \mathrm{dl})$. The HDL-cholesterol and plasma triglyceride levels were not significantly different from the other two study groups. The mean apoLDL concen- 
tration $(362 \pm 126 \mathrm{mg} / \mathrm{dl})$ was nearly threefold greater than in the heterozygotes $(126 \pm 21 \mathrm{mg} / \mathrm{dl})$ and 7.5 -fold greater than in the normals $(48 \pm 6 \mathrm{mg} / \mathrm{dl})$. The slow exponential component of the apoLDL plasma die-away curve was significantly prolonged to $6.0 \pm 0.8 \mathrm{~d}$.

The most striking abnormalities were found in the FCR and the apoLDL synthetic rate. The mean FCR for this group calculated from the plasma die-away curve $(0.176 \pm 0.040 / d)$ was about one-third of normal $(0.450 \pm 0.072 / d)$. As noted with the other two groups, there was good agreement between this value for the FCR and the one calculated from the U:P ratio (Table III). The mean value for the apoLDL synthetic rate was significantly increased $(26.4 \pm 10.0 \mathrm{mg} / \mathrm{kg} / \mathrm{d})$ when compared to either the heterozygotes or normals.

Inasmuch as the group of $\mathrm{FH}$ homozygotes included individuals with each of the three known genotypes found in this disease (Table II), these studies afforded an opportunity to learn whether or not the genotype markedly influenced the LDL turnover parameters. The homozygotes with different genotypes could not be distinguished clinically or by plasma lipoprotein levels manifested during the metabolic studies (Table II). With one exception (D.R.), the values for the FCR were surprisingly similar and fell within a narrow range (0.144-0.179/d) (Table III). The patient, D.R., who exhibited the highest FCR, also exhibited the highest number of LDL receptors on her cultured skin fibroblasts (15-20\% of normal). Except for the value in D.R., the FCR did not appear to differ significantly among the genotypes. The synthetic rate for apoLDL and its intravascular-extravascular distribution also did not differ significantly according to the genotype.

The close relationship between the apoLDL synthetic rate and the plasma apoLDL concentration in the homozygotes is evident from the plot in Fig. 1. A high degree of correlation exists between the apoLDL synthetic rate and the plasma apoLDL concentration $(r=0.943)$. This high degree of correlation is expected when one considers the narrow range of values for the FCR in these patients and points out that the FCR is not the only major determinant of pool size in these patients. A highly significant correlation was also found when the apoLDL synthetic rate was compared to the plasma apoLDL concentration in the heterozygotes ( $r=0.86$; data not shown), again because of the relatively narrow range through which the FCR fluctuates in this group (Table III).

Chemical cholesterol balance. Seven FH homozygotes and four FH heterozygotes were evaluated by chemical cholesterol balance (Table IV). The heterozygotes were selected as "controls" of similar age for the young homozygotes because virtually no chemical cholesterol balance data are available in normal children of this age group. The results in M.C., L.C., and

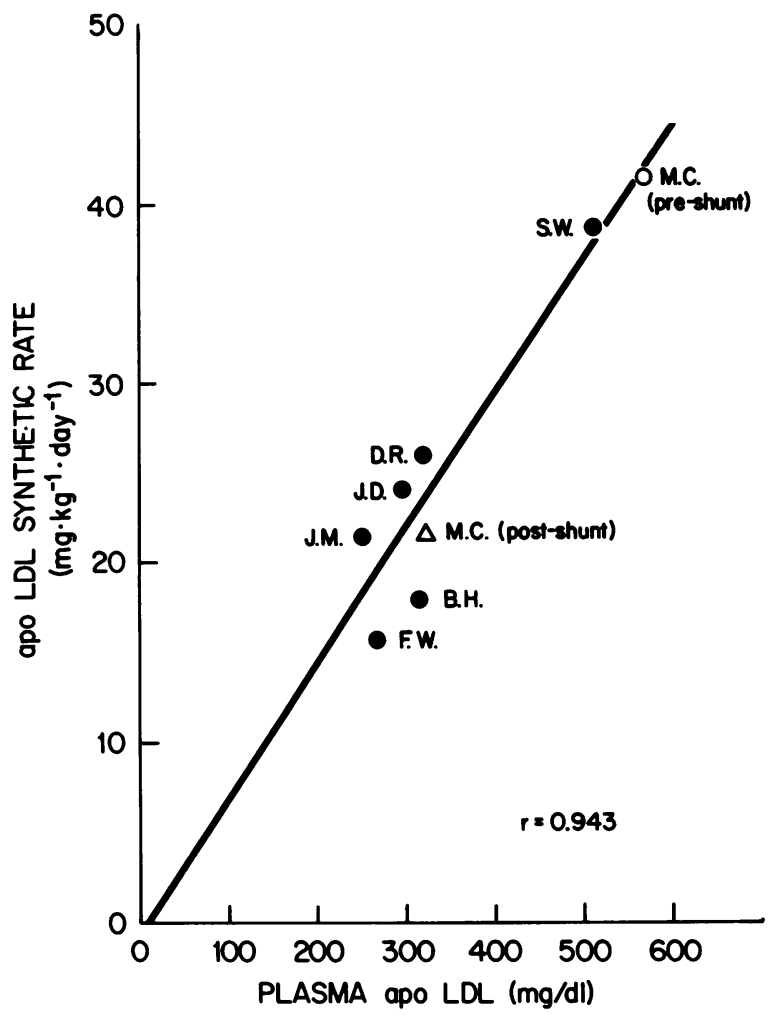

FIGURE 1 The relation between the apoLDL synthetic rates and the plasma apoLDL concentrations in FH homozygotes. Values for the apoLDL synthetic rates and the plasma apoLDL concentrations were obtained during the ${ }^{125}$ I-LDL turnover studies. The values for M.C. both before (O) and after $(\triangle)$ portacaval shunt surgery are shown by the open symbols (11). Individual values are listed in Table III.

Je.Ch. were presented in an earlier report (11). Table IV also contains the summary of unpublished results of chemical cholesterol balance studies in 14 normal adult males performed in San Diego under conditions identical to those employed here. The age range for these subjects was 27-63 yr with a mean age of $50 \mathrm{yr}$.

All patients excreted sterol in excess of their dietary intake, and because there was no reason to suppose that they were losing body cholesterol this excess excretion of sterol represents a minimal estimate for the amount of total cholesterol synthesized per day. As we reported (11), M.C. exhibited a total cholesterol synthetic rate of $22.2 \mathrm{mg} / \mathrm{kg}$ per d, a value approximately twofold greater than normal. Although the percentage of newly synthesized cholesterol converted to bile acids in this patient was relatively low $(1.9 \%)$, her absolute production rate for bile acids $(4.3 \mathrm{mg} / \mathrm{kd}$ per $\mathrm{d})$ was in the range of the "control subjects."

An increased synthetic rate for J.M. was also apparent ( $16.6 \mathrm{mg} / \mathrm{kg}$ per d), but in this case $69.3 \%$ of the total sterol production was in the form of bile acids (11.5 
TABLE IV

Chemical Cholesterol Balance Data

\begin{tabular}{|c|c|c|c|c|c|c|c|c|}
\hline \multirow[b]{2}{*}{ Patient } & \multirow[b]{2}{*}{ Age } & \multirow{2}{*}{$\begin{array}{c}\text { Dietary } \\
\text { cholesterol } \\
\text { intake (a) }\end{array}$} & \multicolumn{3}{|c|}{ Fecal steroid excretion* } & \multirow{2}{*}{$\begin{array}{c}\text { Steroid } \\
\text { balance } \\
\text { (b)-(a) }\end{array}$} & \multicolumn{2}{|c|}{ Synthetic rate } \\
\hline & & & Neutral & Acidic & Total (b) & & Total cholesterol & Bile acids \\
\hline & $y r$ & $m g / d$ & & $m g / d$ & & $m g / d$ & $m g / k_{t}$ & \\
\hline \multicolumn{9}{|l|}{ Homozygotes } \\
\hline M.C. $\$$ & 7 & 109 & $479 \pm 20$ & $88 \pm 18$ & $568 \pm 34$ & $459 \pm 34$ & 22.2 & 4.3 \\
\hline F.W. & 13 & 125 & $646 \pm 82$ & $69 \pm 30$ & $715 \pm 56$ & $590 \pm 56$ & 11.0 & 1.3 \\
\hline B.H. & 21 & 255 & $653 \pm 87$ & $406 \pm 218$ & $1,086 \pm 238$ & $804 \pm 238$ & 8.4 & 4.2 \\
\hline J.M. & 5 & 121 & $207 \pm 3$ & $196 \pm 35$ & $403 \pm 33$ & $282 \pm 33$ & 16.6 & 11.5 \\
\hline S.W. & 6 & 134 & $330 \pm 15$ & $30 \pm 9$ & $360 \pm 17$ & $226 \pm 17$ & 10.6 & 1.4 \\
\hline D.R. & 15 & 125 & $555 \pm 75$ & $202 \pm 73$ & $757 \pm 90$ & $632 \pm 90$ & 13.2 & 4.2 \\
\hline J.D. & 15 & 143 & $495 \pm 83$ & $297 \pm 46$ & $792 \pm 85$ & $649 \pm 85$ & 11.4 & 5.2 \\
\hline Mean \pm SD & & & & & & & $13.3 \pm 4.7$ & $4.6 \pm 3.4$ \\
\hline \multicolumn{9}{|c|}{ Heterozygotes } \\
\hline K.M. & 8 & 166 & $268 \pm 8$ & $111 \pm 6$ & $379 \pm 7$ & $213 \pm 7$ & 8.1 & 4.2 \\
\hline L.C. $\$$ & 11 & 145 & $363 \pm 20$ & $94 \pm 35$ & $456 \pm 44$ & $311 \pm 44$ & 10.0 & 3.0 \\
\hline Je.Ch. $\S$ & 12 & 193 & $368 \pm 72$ & $250 \pm 82$ & $635 \pm 91$ & $442 \pm 91$ & 10.8 & 6.1 \\
\hline M.M. & 31 & 182 & $333 \pm 11$ & $377 \pm 53$ & $712 \pm 50$ & $530 \pm 50$ & 10.8 & 7.7 \\
\hline Mean $\pm S D$ & & & & & & & $9.9 \pm 1.3$ & $5.3 \pm 2.1$ \\
\hline \multicolumn{9}{|l|}{ Normals" } \\
\hline$n=14$ & $\begin{array}{c}50 \\
(27-63)\end{array}$ & & & & & & $9.6 \pm 2.3$ & $4.9 \pm 2.3$ \\
\hline
\end{tabular}

* Values are the mean \pm 1 SD of serial stool collection periods.

$\downarrow$ The synthetic rate of total cholesterol was determined by dividing the mean total steroid balance (b) by the body weight (Table I). The synthetic rate of bile acids was determined by dividing the mean bile acid excretion (acidic fecal steroid excretion) by the body weight. The values for total cholesterol synthesis include values for both neutral sterols and bile acids.

$\$$ From reference 11 .

"Unpublished data on 14 normal male subjects studied in San Diego by S. M. Grundy under experimental conditions identical to those used here. The mean age for the group was $50 \mathrm{yr}$. The values for total cholesterol and bile acid synthetic rates are the mean \pm 1 SD for the group. Diet composition was as described in reference 15 .

$\mathrm{mg} / \mathrm{kg}$ per d). The five other FH homozygotes did not overproduce cholesterol, but two subjects, F.W. and S.W., had low values for bile acid synthesis ( 1.3 and 1.4 $\mathrm{mg} / \mathrm{kg}$ per d, respectively). Therefore, only two of the seven homozygotes (one receptor-negative and one receptor-defective) exhibited cholesterol overproduction and no consistent trend in the absolute rate of bile acid excretion was observed.

\section{DISCUSSION}

A systematic investigation of well-characterized patients with either heterozygous or homozygous $\mathrm{FH}$ has been performed to evaluate the influence of the gene-dosage effect on certain parameters of cholesterol and lipoprotein metabolism in vivo. The results can be summarized as follows: homozygotes with FH exhibit a threefold increase in apoLDL synthesis, whereas the fractional catabolic rate for the apoprotein is only about one-third of normal (Figs. 2 and 3). Heterozygotes, with one dose of the mutant FH gene, exhibit intermediate values for both parameters: their synthetic rate for apoLDL is 1.7-fold above normal and their fractional catabolic rate for apoLDL is about two-thirds of normal (Figs. 2 and 3 ).

Among the FH homozygotes, these defects appeared equally severe whether the subjects belonged to the receptor-negative class, the receptor-defective class, or the internalization-defective class. Similar results in FH homozygotes have been reported previously $(9-11)$ as has the reduced FCR in FH heterozygotes

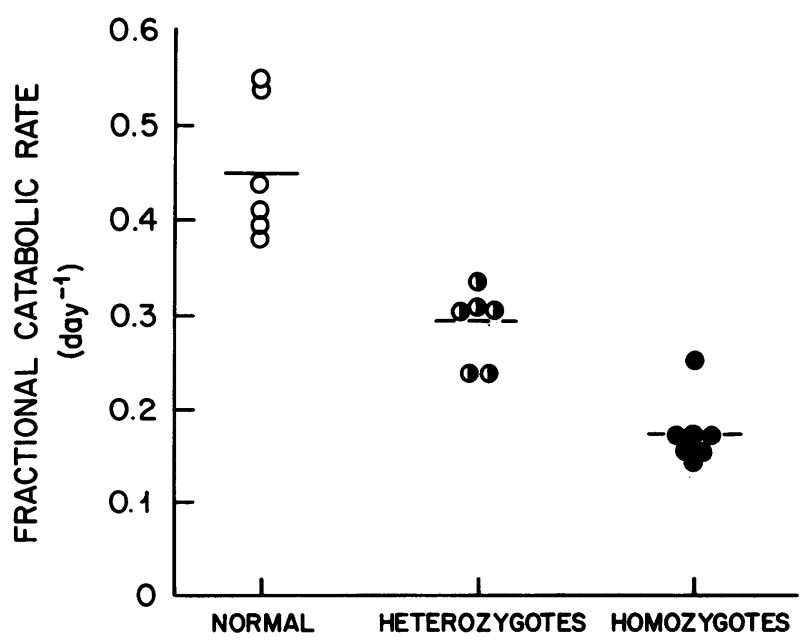

FIGURE 2 FCR of apo-LDL in normals, FH heterozygotes, and FH homozygotes. The FCR calculated from the plasma die-away curve for ${ }^{125}$ I-LDL is plotted for each subject. The mean value for each group is indicated by the solid line. Individual values are listed in Table III. 


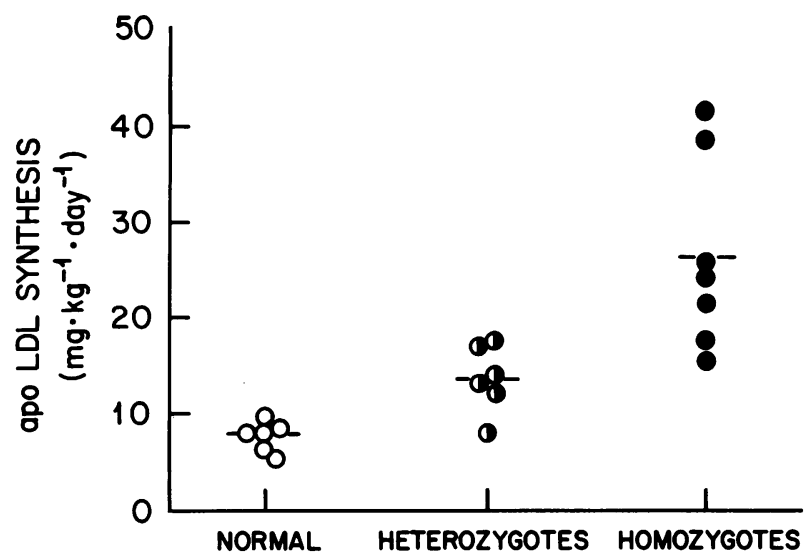

FIGURE 3 ApoLDL synthesis in normals, heterozygotes, and homozygotes. ApoLDL synthesis determined by ${ }^{125}$ I-LDL turnover is plotted for each subject. The mean value for each group is indicated by the solid line. Individual values are listed in Table III.

$(8,11,23)$. Overproduction of apoLDL in FH heterozygotes has not been consistently found ( 8 ) but a trend toward overproduction was noted in affected members of a family with FH who were studied on an outpatient basis (23).

Because the FH homozygotes overproduced apoLDL by threefold in the steady state, their absolute catabolic rate for apoLDL was also increased by threefold. In this setting the reduced fractional catabolic rate might reflect the saturation of normal catabolic pathways rather than the altered clearance of apoLDL by faulty cell surface receptors. Several lines of evidence suggest that the decreased FCR results from altered clearance of apoLDL caused by abnormal receptor activity. First, the FCR for LDL appears to be fixed in FH homozygotes at $\cong 17 \% /$ d. Thus, among $\mathrm{FH}$ homozygotes whose plasma apoLDL levels varied from 250 to $569 \mathrm{mg} / \mathrm{dl}$, the FCR showed little variation from the mean of $17 \% / d$, whereas the absolute synthetic and degradative rate for LDL varied nearly threefold $(15.6-41.6 \mathrm{mg} / \mathrm{kg}$ per $\mathrm{d})$, indicating that the variation in plasma LDL levels observed in these patients is caused by the variation in the plasma apoLDL synthetic rates (Fig. 1). Second, a similar phenomenon was seen in FH heterozygotes in whom the values for apoLDL synthetic rates varied widely (Table II). Third, observations that portacaval shunt surgery (Fig. 1) (11) and plasmapheresis (24) in FH homozygotes lower the plasma apoLDL level without affecting the FCR for apoLDL are also consistent with the interpretation that the diminished FCR is a consequence of the genetic defect in FH.

Considered together, the currently available data indicate that the primary genetic defect in $\mathrm{FH}$ produces two distinct abnormalities of LDL metabolism: an increase in the synthetic rate for apoLDL and a decrease in the efficiency of apoLDL catabolism. The reduced FCR, which is more severe in FH homozygotes than in FH heterozygotes, correlates directly with the number of functional cellular LDL receptors, which is more severely reduced in homozygotes than in heterozygotes $(3,14)$. The mechanism by which a deficiency of LDL receptors causes an increased synthesis of LDL has not been defined. It has been postulated on the basis of genetic reasoning that an LDL receptor may normally exist on liver cells and that one of its functions is to monitor the plasma level of LDL and to suppress production of that lipoprotein $(10,25,26)$ or its precursor, very low-density lipoprotein (VLDL). The absence of such an LDL receptor in liver cells of FH homozygotes would cause the liver to sense a deficiency of LDL in plasma and thereby to secrete the lipoprotein directly into plasma $(10,25,26)$. Indeed, recent studies by Soutar et al. (27) show that in FH homozygotes, in contrast to normal subjects, a considerable portion of LDL is secreted directly into plasma without passing through VLDL.

With respect to cholesterol synthesis as determined by the sterol balance technique, the current data show no clear-cut differences between normals and patients with either one or two FH genes. Previous studies using techniques similar to those employed in this study have also failed to demonstrate a difference in sterol balance between normal and presumptive FH heterozygotes (28-32). Metabolic studies of cholesterol turnover (33) and cholesterol balance $(11,34,35)$ in $\mathrm{FH}$ homozygotes have not yielded consistent or significant abnormalities in the rate of total body cholesterol production. Of the six homozygotes previously studied $(11,33-35)$, three had increased synthesis $(17.0,17.1$, and $22.2 \mathrm{mg} / \mathrm{kg}$ per d), whereas the other three exhibited normal cholesterol production. There was no clear reason for this difference although those patients with increased synthesis were younger $(7,10$, and $12 \mathrm{yr})$ than the other patients $(14,15$, and $18 \mathrm{yr})$, and sterol production and excretion may be increased in children as compared to adults (36).

Two of our FH homozygotes exhibited low values for bile acid synthesis. Low bile acid synthesis has been observed by others in some patients with FH (37-39) but it is unlikely that this inconstant finding plays a role in the pathogenesis of this disease for several reasons. First, cholestyramine treatment increases fecal bile acid excretion in FH homozygotes to the same degree as it does in normal subjects (40). Second, complete biliary diversion increased bile acid excretion markedly in two FH homozygotes without altering the plasma cholesterol level (41). Third, feeding bile acids to patients with FH does not materially influence the plasma cholesterol level (42).

In the face of a normal rate of total, body cholesterol 
synthesis, the threefold overproduction of LDL in FH homozygotes indicates that these individuals must reuse much of the cholesterol that is liberated from LDL degradation. To illustrate this point, one can compare the average daily turnover to LDL-cholesterol with total body cholesterol production in a hypothetical 70-kg FH homozygote. The mean apoLDL turnover in a 70-kg man would be $1,848 \mathrm{mg}$ apoLDL/d $(26.4 \mathrm{mg} / \mathrm{kg}$ per $\mathrm{d} \times 70 \mathrm{~kg}$ ), which equals $3,086 \mathrm{mg}$ LDL-cholesterol/d if one assumes that LDL contains an average of $1.67 \mathrm{mg}$ of cholesterol for every $\mathrm{mg}$ of protein. The mean total body cholesterol synthetic rate for the homozygotes in this study is $13.3 \mathrm{mg} / \mathrm{kg}$ per $\mathrm{d}$ (Table IV) which equals $931 \mathrm{mg} / \mathrm{d}$ in a 70-kg man. In this example, the amount of LDL-cholesterol transported through the plasma space each day is threefold greater than the total amount produced daily by the body.

\section{ACKNOWLEDGMENTS}

We thank Mr. G. Michael Funk, Mr. Scott Madison, Ms. Charlene McCoy, and Ms. LeAnna Johansen for their expert technical assistance, Ms. Carolyn Tirado for preparation of the manuscript, Dr. Joan Reisch for guidance in performing the statistical analyses, and the staffs of both Clinical Research Centers for their role in the performance of these studies. We thank the following physicians for their referral of patients to this study: Doctors Bruce A. Kottke, James R. Osborn, Reynold S. Shirai, Joseph E. Loewenstein, Michael F. Sorrell, and Carol R. Angle. Lastly, we thank Dr. Michael S. Brown and Dr. Joseph L. Goldstein for performing the tissue culture studies on these patients and for their many helpful suggestions during the course of this work.

This research was supported in part by the Medical Research Service of the Veterans Administration and by the following grants from the National Institutes of Health: 5-R01HL15949, 5-M01-RR00633, P01-HL20948, HL-14197, AM16667 , and RR-48.

\section{REFERENCES}

1. Brown, M. S., and J. L. Goldstein. 1975. Familial hypercholesterolemia: genetic, biochemical, and pathophysiologic considerations. Adv. Intern. Med. 20: 273-296.

2. Fredrickson, D. S., J. L. Goldstein, and M. S. Brown. 1978. The familial hyperlipoproteinemias. In The Metabolic Basis of Inherited Disease. J. B. Stanbury, J. B. Wyngaarden, and D. S. Fredrickson, editors. McGraw-Hill, Inc., New York. 4th edition. 604-655.

3. Goldstein, J. L., and M. S. Brown. 1977. The low density lipoprotein pathway and its relation to atherosclerosis. Annu. Rev. Biochem. 46: 897-930.

4. Goldstein, J. L., and M. S. Brown. 1974. Binding and degradation of low density lipoproteins by cultured human fibroblasts: comparison of cells from a normal subject and from a patient with homozygous familial hypercholesterolemia. J. Biol. Chem. 249: 5153-5162.

5. Ho, Y. K., M. S. Brown, D. W. Bilheimer, and J. L. Goldstein. 1976. Regulation of low density lipoprotein receptor activity in freshly isolated human lymphocytes. J. Clin. Invest. 58: 1465-1474.

6. Ho, Y. K., J. R. Faust, D. W. Bilheimer, M. S. Brown, and J. L. Goldstein. 1977. Regulation of cholesterol synthesis by low density lipoprotein in isolated human lymphocytes. J. Exp. Med. 145: 1531-1549.

7. Bilheimer, D. W., Y. K. Ho, M. S. Brown, R. G. W. Anderson, and J. L. Goldstein. 1978. Genetics of the low density lipoprotein receptor: diminished receptor activity in lymphocytes from heterozygotes with familial hypercholesterolemia. J. Clin. Invest. 61: 678-696.

8. Langer, T., W. Strober, and R. I. Levy. 1972. The metabolism of low density lipoprotein in familial type II hyperlipoproteinemia. J. Clin. Invest. 51: 1528-1536.

9. Reichl, D., L. A. Simons, and N. B. Myant. 1974. The metabolism of low-density lipoprotein in a patient with familial hyperbetalipoproteinemia. Clin. Sci. Mol. Med. 47: 635-638.

10. Simons, L. A., D. Reichl, N. B. Myant, and M. Mancini. 1975. The metabolism of the apoprotein of plasma low density lipoprotein in familial hyperbetalipoproteinemia in the homozygous form. Atherosclerosis. 21: 283-298.

11. Bilheimer, D. W., J. L. Goldstein, S. M. Grundy, and M. S. Brown. 1975. Reduction in cholesterol and low density lipoprotein synthesis after portacaval shunt surgery in a patient with homozygous familial hypercholesterolemia. J. Clin. Invest. 56: 1420-1430.

12. Goldstein, J. L., S. E. Dana, G. Y. Brunschede, and M. S. Brown. 1975. Genetic heterogeneity in familial hypercholesterolemia: evidence for two different mutations affecting functions of low density lipoprotein receptor. Proc. Natl. Acad. Sci. U. S. A. 72: 1092-1096.

13. Brown, M. S., and J. L. Goldstein. 1976. Analysis of a mutant strain of human fibroblasts with a defect in the internalization of receptor-bound low density lipoprotein. Cell. 9: 663-674.

14. Goldstein, J. L., M. S. Brown, and N. J. Stone. 1977. Genetics of the LDL receptor: evidence that the mutations affecting binding and internalization are allelic. Cell. 12: 629-641.

15. Grundy, S. M. 1975. Effects of polyunsaturated fats on lipid metabolism in patients with hypertriglyceridemia. J. Clin. Invest. 55: 269-282.

16. Noble, R. P. 1968. Electrophoretic separation of plasma lipoproteins in agarose gel. J. Lipid Res. 9: 693-700.

17. Hatch, F. T., and R. S. Lees. 1968. Practical methods for plasma lipoprotein analyses. Adv. Lipid Res. 6: 1-68.

18. Brown, M. S., S. E. Dana, and J. L. Goldstein. 1974. Regulation of 3-hydroxy-3-methylglutaryl coenzyme A reductase activity in cultured human fibroblasts. Comparison of cells from a normal subject and from a patient with homozygous familial hypercholesterolemia. J. Biol. Chem. 249: 789-796.

19. Steinfeld, J. L., R. R. Paton, A. L. Flick, R. A. Milch, F. E. Beach, and D. L. Tabern. 1957. Distribution and degradation of human serum albumin labelled with $I^{133}$ by different techniques. Ann. N. Y. Acad. Sci. 70: 109-121.

20. Quintão, E., S. M. Grundy, and E. H. Ahrens, Jr. 1971. An evaluation of four methods for measuring cholesterol absorption by the intestine in man. J. Lipid Res. 12: 221-232.

21. Zar, J. 1974. Biostatistical Analysis. Prentice-Hall, Inc., Englewood Cliffs, N. J. 130-162.

22. Connor, W. E. 1976. Dietary lipids, hyperlipidemia, and atherosclerosis. In Cerebrovascular Diseases. P. Scheinberg, editor. Raven Press, New York. 121-135.

23. Packard, C. J., J. L. H. C. Third, J. Shepherd, A. R. Loumer, H. G. Morgan, and T. D. V. Lawrie. 1976. Low density lipoprotein metabolism in a family of familial hypercholesterolemia patients. Metabolism Clin. Exp. 25: 9951006.

24. Thompson, G. R., T. Spinks, A. Ranicar, and N. B. Myant. 
1977. Non-steady-state studies of low-density-lipoprotein turnover in familial hypercholesterolemia. Clin. Sci. Mol. Med. 52: 361-369.

25. Brown, M. S., and J. L. Goldstein. 1976. Familial hypercholesterolemia: a genetic defect in the low-density lipoprotein receptor. N. Engl. J. Med. 294: 1386-1390.

26. Bilheimer, D. W. 1977. Needed: new therapy for hypercholesterolemia. N. Engl. J. Med. 296: 508-509.

27. Soutar, A. K., N. B. Myant, and G. R. Thompson. 1977. Simultaneous measurement of apolipoprotein B turnover in very-low- and low-density lipoproteins in familial hypercholesterolemia. Atherosclerosis. 28: 247-256.

28. Quintāo, E., S. M. Grundy, and E. H. Ahrens, Jr. 1971. Effects of dietary cholesterol on the regulation of total body cholesterol in man. J. Lipid. Res. 12: 233-247.

29. Grundy, S. M., and E. H. Ahrens, Jr. 1969. Measurement of cholesterol turnover, synthesis, and absorption in man, carried out by isotope kinetic and sterol balance methods. J. Lipid Res. 10: 91-107.

30. Grundy, S. M., E. H. Ahrens, Jr., and J. Davignon. 1969. The interaction of cholesterol absorption and cholesterol synthesis in man. J. Lipid Res. 10: 304-315.

31. Grundy, S. M., and E. H. Ahrens, Jr. 1970. The effects of unsaturated dietary fats on absorption, excretion, synthesis, and distribution of cholesterol in man. J. Clin. Invest. 49: 1135-1152.

32. Grundy, S. M., E. H. Ahrens, Jr., G. Salen, P. H. Schreibman, and P. J. Nestel. 1972. Mechanism of action of clofibrate on cholesterol metabolism in patients with hyperlipidemia. J. Lipid Res. 13: 531-551.

33. Lewis, B., and N. B. Myant. 1967. Studies in the metabolism of cholesterol in subjects with normal plasma cholesterol levels and in patients with essential hypercholesterolemia. Clin. Sci. (Oxf.) 32: 201-213.
34. Grundy, S. M., E. H. Ahrens, Jr., and G. Salen. 1971. Interruption of the enterohepatic circulation of bile acids in man: comparative effects of cholestyramine and ileal exclusion on cholesterol metabolism. J. Lab. Clin. Med. 78: $94-121$.

35. Miettinen, T. A. 1978. New insights into cholesterol dynamics. Arch. Surg. 113: 45-49.

36. Huang, C. T. L., J. T. Rodriguez, W. E. Woodward, and B. L. Nichols. 1976. Comparison of patterns of fecal bile acids and neutral sterol between children and adults. Am. J. Clin. Nutr. 29: 1196-1203.

37. Miettinen, T. A., R. Pelkonen, E. A. Nikkila, and D. Heinonen. 1967. Low excretion of fecal bile acids in a family with hypercholesterolemia. Acta Med. Scand. 182: 645-650.

38. Kottke, B. A. 1969. Differences in bile acid excretion: Primary hypercholesterolemia compared to combined hypercholesterolemia and hypertriglyceridemia. Circulation. 40: 13-20.

39. Einarsson, K, and K. Helström. 1972. The formation of bile acids in patients with three types of hyperlipoproteinemia. Eur. J. Clin. Invest. 2: 225-230.

40. Moutafis, C. D., L. A. Simons, N. B. Myant, P. W. Adams, and V. Wynn. 1977. The effect of cholestyramine on the faecal excretion of bile acids and neutral steroids in familial hypercholesterolemia. Atherosclerosis. 26: 329334.

41. Deckelbaum, R. J., R. S. Lees, D. M. Small, S. E. Hedberg, and S. M. Grundy. 1977. Failure of complete bile diversion and oral bile acid therapy in the treatment of homozygous familial hypercholesterolemia. N. Engl. J. Med. 296: 465-470.

42. Tangedahl, T. N., A. F. Hofmann, and B. A. Kottke. 1979. Biliary lipid secretion in hypercholesterolemia. J. Lipid Res. 20: 125-133. 